\title{
Detection of Secondary Causes and Coexisting Diseases in Hypertensive Patients: OSA and PA Are the Common Causes Associated with Hypertension
}

\author{
Lei Wang, Nanfang Li, Xiaoguang Yao, Guijuan Chang, Delian Zhang, \\ Mulalibieke Heizhati, Menghui Wang, Qin Luo, and Jianqiong Kong

\begin{abstract}
Hypertension Institute of Xinjiang, Hypertension Center of the People's Hospital of Xinjiang Uygur Autonomous Region, Urumqi, China
\end{abstract}

Correspondence should be addressed to Nanfang Li; lnanfang2010@sina.com

Received 7 October 2016; Revised 19 February 2017; Accepted 16 March 2017; Published 13 June 2017

Academic Editor: Kazim Husain

Copyright (C) 2017 Lei Wang et al. This is an open access article distributed under the Creative Commons Attribution License, which permits unrestricted use, distribution, and reproduction in any medium, provided the original work is properly cited.

\begin{abstract}
Background. Since the control rate of blood pressure is lower in mainland China, the aim of this study is to investigate the proportion of secondary causes and coexisting diseases of hypertension in hypertensive patients. Methods. Data on consecutive patients with hypertension who visited the Hypertension Center. Diseases were detected using an established strict screening protocol. Results. Detection rate of secondary causes and coexisting diseases of hypertension was $39.5 \%$ among 3003 hypertensive patients. Obstructive sleep apnea (OSA) was the most common, accounting for $24.7 \%$ of patients, followed by primary aldosteronism (PA) (5.8\%) and PA + OSA (4.9\%). Endocrine hypertension accounted for $12.1 \%$ of patients, including $10.7 \%$ of patients with PA, $1.1 \%$ with hypothyroidism, $0.1 \%$ with pheochromocytoma, $0.1 \%$ with Cushing's syndrome, and $0.1 \%$ with hyperthyroidism, respectively. Those who smoke, those who are obese, and those who have diabetes accounted for $31.3 \%$, 27.5\%, and $16.6 \%$ of total patients, respectively. There were overlapping conditions in secondary causes and coexisting diseases of hypertension. OSA was the most common in each age- and BMI-stratified group. Conclusion. Findings from the current study suggest an increasing frequency of secondary forms of hypertension, highlighting the burden of OSA and PA in hypertensive patients.
\end{abstract}

\section{Introduction}

Hypertension is a major modifiable risk factor for morbidity and mortality of cardiocerebrovascular diseases and renal failure [1]. The control of blood pressure (BP) can reduce the risk of cardiocerebrovascular diseases, as confirmed by numerous studies and mentioned by a number of guidelines. However, the control rate of BP is lower although a lot of effort has been made [2]. A recent large-scale systemic analysis using data generated in mainland China between 2003 and 2012 showed that, among hypertensive patients, only $44.6 \%$ were aware of their condition, $35.2 \%$ were taking antihypertensive medication, and $11.2 \%$ achieved adequate $\mathrm{BP}$ control [3]. All this information poses the question why it is difficult for BP to reach target range and whether there are secondary causes and coexistence of some other diseases which evaluate BP and affect negatively BP control in hypertensive patients. Studies have shown that, in addition to genetic and environmental factors, a number of diseases increase $\mathrm{BP}$, and their wide distributions in such various systems as endocrine and respiratory, renal, and vascular ones and psychological factors like anxiety have led to lower awareness or underestimation of these conditions by the cardiologists who mostly deal with hypertensive patients. A few studies on this aspect have mainly focused on the prevalence of secondary causes and coexisting diseases in resistant hypertension $[4,5]$. Most importantly, the data are lacking, generated by comprehensive systemic specialty settings on secondary causes and coexisting diseases in hypertensive patients extensive in sample and investigated systematically.

The specialty center, Hypertension Center of a provincial general hospital of Xinjiang, Northwest of China, in which this study is conducted provides diagnosis and individualized 
treatment to hypertensive population in this region, particularly screening, diagnosis, and treatment service of secondary causes and coexisting diseases of hypertension including endocrine diseases such as primary aldosteronism, Cushing's syndrome, pheochromocytoma, and thyroid dysfunctions; respiratory diseases like obstructive sleep apnea; psychological factors such as anxiety; renal disease; and vascular diseases.

The aim of this study is to evaluate the proportion of secondary causes and coexisting diseases of hypertension in those who visited the center with the main complaint of elevated BP.

\section{Materials and Methods}

2.1. Patient Selection. Consecutive patients with hypertension referred to Hypertension Center of the People's Hospital of Xinjiang Uygur Autonomous Region, China, since January to December 2010, meeting the following inclusion criteria, were included into the current study. Inclusion criteria were as follows: age $\geq 18$ years, new onset hypertension, previously diagnosed hypertension on antihypertensive treatment, or $\mathrm{BP}$ could not reach target $(\mathrm{SBP}<140 \mathrm{mmHg}$ and/or DBP $<$ $90 \mathrm{mmHg}$ ) if without antihypertensive treatment. This study was approved by the Hospital Ethics Committee, and all patients provided written informed consent.

2.2. Office BP Measurements. Hypertension was defined according to the criteria established by the Seventh Report of the Joint National Committee on Prevention, Detection, Evaluation, and Treatment of High Blood pressure [6]. Office blood pressure measurement was based on the recommendation [7].

2.3. Primary Evaluation. A complete history and physical examination were performed by specialists in the clinic. Laboratory tests include measurements of serum electrolytes, creatinine, blood glucose, cholesterol (TC), triglycerides (TG), high density lipoprotein cholesterol (HDL-c), low density lipoprotein cholesterol (LDL-c), and hemoglobin, as well as tests for proteinuria and urinary sediment. Electrocardiogram and renal ultrasound were recorded in all patients. Patients with suspicious symptoms, signs, and laboratory examinations were suggested for further evaluation of secondary causes of hypertension, with particular attention given to the following: the age $<30$ years at onset of hypertension, resistant hypertension, severe hypertension or hypertensive emergencies, sudden increase of BP in a previously stable patient, accelerated hypertension, severe target organ damage not matched for the duration of high $\mathrm{BP}$, hypertension with adrenal incidentaloma, exaggerated diurnal sleepiness, nocturnal snoring, paroxysmal hypertension, hematuria, proteinuria, increased serum creatinine, hypokalemia, an abdominal bruit, particularly when diastolic, differences of $>1.5 \mathrm{~cm}$ in the length between the two kidneys via renal ultrasound, and so forth [8]. The procedure for screening of secondary causes and coexisting diseases of hypertension was presented in Figure 1.

\subsection{Further Evaluation for Secondary Causes and Coexisting Diseases of Hypertension}

2.4.1. Renal Parenchymal Disease (RPD). Patients were diagnosed with hypertension after a renal disease history. These patients also had abnormalities of urinary sediment including hematuria and proteinuria, and serum creatinine in the upright position ( $>177 \mathrm{umol} / \mathrm{L}$ ) and/or pathological diagnosis after kidney biopsy and/or imaging showed abnormalities in morphology and structure of kidney.

2.4.2. Renal Artery Stenosis (RAS). Renal artery stenosis was confirmed by angiogram and/or computed tomography angiography (CTA). Angiostenosis > 50\% was confirmed positive [9].

2.4.3. Primary Aldosteronism (PA). The screening process and diagnosis of PA was made based on 2008 endocrine society's guideline [10] and on the previous studies conducted in our center [11]. A suppressed PRA $\left(<1.0 \mathrm{ug} \cdot \mathrm{L}^{-1} \cdot \mathrm{h}^{-1}\right)$ in addition to an elevated aldosterone level $\left(>12 \mathrm{ng} \cdot \mathrm{L}^{-1}\right)$ or an ARR (the PAC to PRA ratio) greater than $20 \mathrm{ng} / \mathrm{dl}$ per $\mathrm{ng} / \mathrm{ml} / \mathrm{h}$ was considered suggestive of PA. PA was confirmed with saline infusion test. Adrenal vein sampling (AVS) was conducted to identify bilateral or unilateral subtypes of PA.

2.4.4. Pheochromocytoma (PHEO). Diagnosis of pheochromocytoma was based on elevated plasma metanephrines and normetanephrines, localization of the tumor was visualized by CT, magnetic resonance imaging (MRI), ${ }^{131} \mathrm{I}-$ meta-iodobenzyl guanidine scanning, and PET-CT [12]. And final confirmation was made by pathological examination (adenoma adrenal medullary).

2.4.5. Cushing's Syndrome (CS). Cushing's syndrome was diagnosed on hormonal assessments, including nonsuppressible serum cortisol after $1 \mathrm{mg}$ of overnight dexamethasone and $48 \mathrm{~h}$ low-dose $(2 \mathrm{mg}$ ) dexamethasone suppression tests. The diagnosis of location was based on the measurement of ACTH levels, a $48 \mathrm{~h}$ high-dose $(8 \mathrm{mg})$ dexamethasone suppression test, and CT/MRI. A cortisol level higher than $5 \mathrm{ug} / \mathrm{dl}$ was not considered suppressed (a positive result) [13].

2.4.6. Thyroid Dysfunction. Serum thyrotropin (TSH), free thyroxine (FT4), and triiodothyronine (FT3) levels were measured. The cut-off levels for TSH were $<0.35 \mathrm{IU} / \mathrm{dl}$ for hyperthyroidism and $>5.5 \mathrm{IU} / \mathrm{dl}$ for hypothyroidism. The cut-off levels for FT4 were <11.5 ng/dl for hypothyroidism and $>22.7 \mathrm{ng} / \mathrm{dl}$ for hyperthyroidism. The cut-off levels for FT3 were $<3.0 \mathrm{ng} / \mathrm{dl}$ for hypothyroidism and $>9.2 \mathrm{ng} / \mathrm{dl}$ for hyperthyroidism.

2.4.7. Obstructive Sleep Apnea (OSA). All patients suspicious of OSA underwent full-night polysomnography. Diagnosis of OSA was based on 2009 clinical guideline of American Academy of Sleep Medicine [14]. OSA was diagnosed when apnea-hypopnea index (AHI) was $\geq 5$ events/hour sleep.

2.4.8. Anxiety. Patients with excessive anxiety, fear, worry, avoidance, and compulsive rituals as well as sleeplessness, 


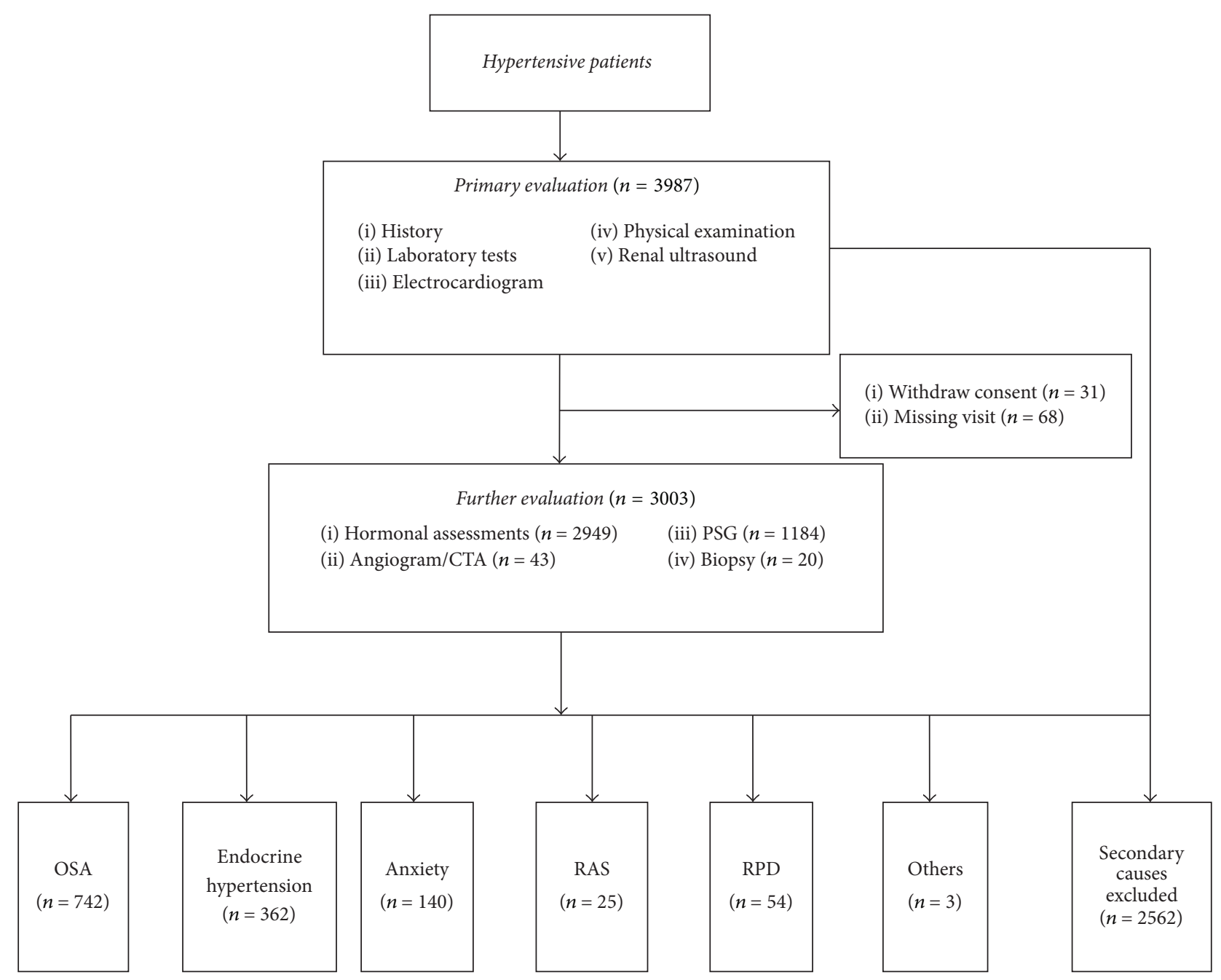

FIGURE 1: Study flow chart. PSG, polysomnography; CTA, computed tomography angiography; OSA, obstructive sleep apnea; RPD, renal parenchymal disease; RAS, renal artery stenosis.

vague pains, headaches, dizziness, stomach upset, or other somatic symptoms but no parenchymal disease were considered to have anxiety disorders. The Hamilton Anxiety Scale was used to assess the degree of anxiety disorders. The diagnosis was based on clinical practice guidelines [15] and the psychiatrist's decision. Moreover, BP values achieved the target $(<140 / 90 \mathrm{mmHg})$ after antianxiety treatment for patients diagnosed as having anxiety in our study.

2.4.9. Aortic Coarctation. If patients complained of both fatigued lower extremities, pulse palpation of arteria cruralis and arteria poplitea were decreased, or if the blood pressure values for the upper extremities are greater than that in the lower ones, then aortic coarctation was considered the probable cause. Then CTA was performed for definite diagnosis of aortic coarctation in these specific subjects.

2.4.10. Others. Liddle's syndrome and polycystic ovary syndrome were diagnosed according to the published literature $[16,17]$.
2.5. Statistical Analysis. Analysis was performed with the Statistical Package for the Social Sciences, version 17.0. statistical software. The results were expressed for continuous variables with a normal distribution as the mean and standard deviation (SD). Qualitative variables were expressed as frequencies. The independent Student's $t$-test was used to estimate differences between two independent groups. Comparison of frequencies was performed by the Pearson $\chi^{2}$ test. A $P$ value $<0.05$ was considered significant.

\section{Results}

3987 hypertensive patients were evaluated during the 12month study period, of whom 3003 patients (mean age: 52 years) were suggested for further evaluation of secondary causes or coexisting diseases of hypertension, including 1597 males and 1406 females. Study flow chart was shown in Figure 1 and the general characteristics of the study population were summarized in Table 1. 


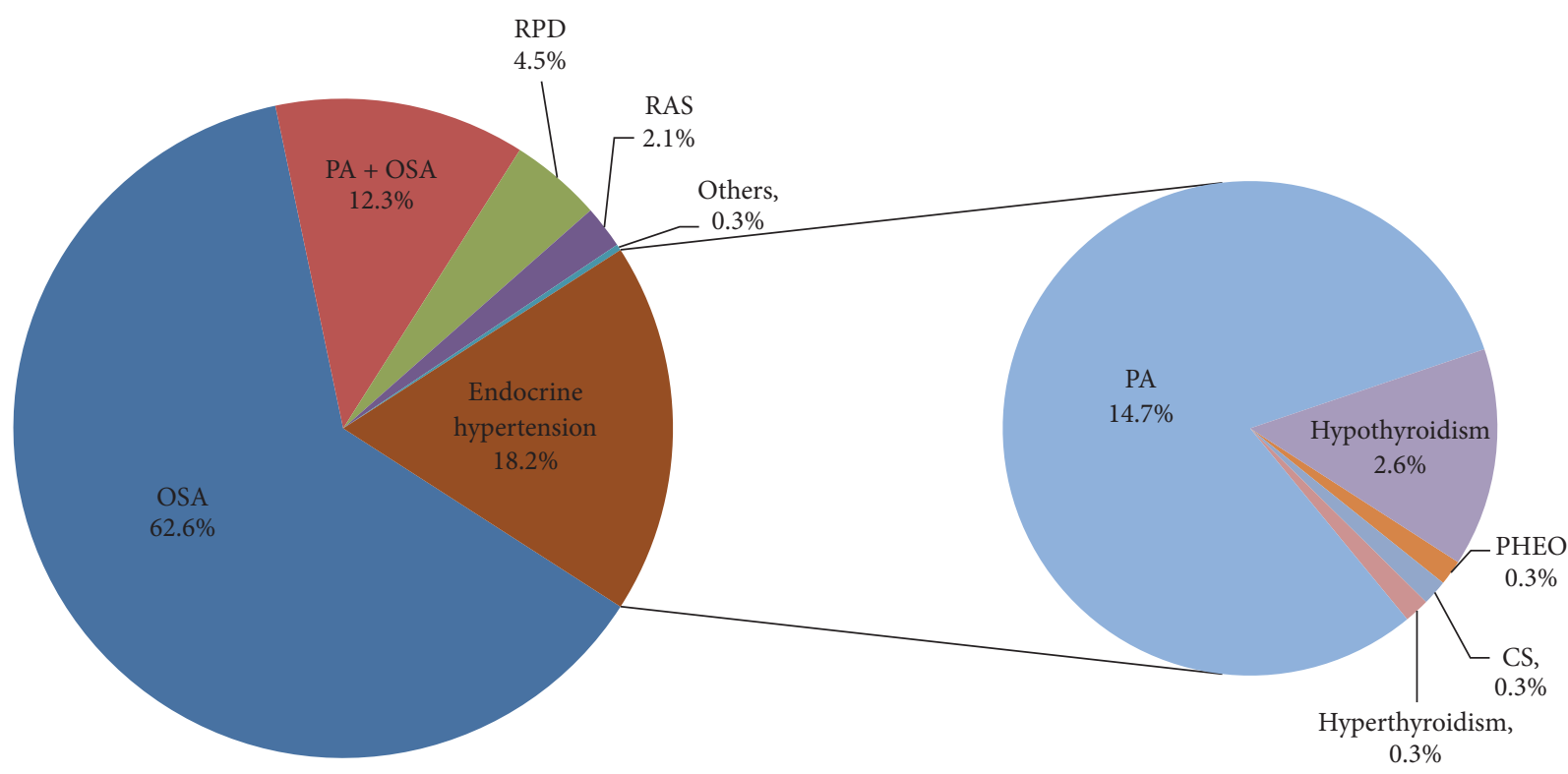

FIGURE 2: Constituent ratio in 1186 patients with secondary causes and coexisting disease. OSA, obstructive sleep apnea; PA, primary aldosteronism; RPD, renal parenchymal disease; RAS, renal artery stenosis; PHEO, pheochromocytoma; CS, Cushing's syndrome.

TABLE 1: Clinical and biochemical characteristics of all subjects $(n=$ 3987).

\begin{tabular}{lc}
\hline Variable & Characteristics \\
\hline Age (years) & $52.0 \pm 13.1$ \\
Male $N, \%$ & $2121(53.2)$ \\
Current smoker, $N(\%)$ & $1248(31.3)$ \\
Current drinker, $N(\%)$ & $1100(27.6)$ \\
BMI, $\left(\mathrm{kg} / \mathrm{m}^{2}\right)$ & $26.9 \pm 4.0$ \\
Office SBP (mmHg) & $141.7 \pm 21.5$ \\
Office DBP (mmHg) & $91.1 \pm 14.8$ \\
Heart rate (beats per min) & $77.8 \pm 9.3$ \\
Serum potassium (mmol/l) & $3.9 \pm 0.4$ \\
Fasting blood glucose (mmol/l) & $5.3 \pm 1.5$ \\
TC (mmol/l) & $4.5 \pm 1.0$ \\
TG (mmol/l) & $2.0 \pm 1.5$ \\
HDL-C (mmol/l) & $1.2 \pm 0.5$ \\
LDL-C (mmol/l) & $2.5 \pm 0.7$ \\
Diabetes mellitus, $N(\%)$ & $662(16.6)$ \\
Coronary artery disease, $N(\%)$ & $746(18.7)$ \\
Stroke history, $N(\%)$ & $1132(28.4)$ \\
Obesity, $N(\%)$ & $1097(27.5)$ \\
Anxiety, $N(\%)$ & $140(3.5)$ \\
\hline
\end{tabular}

Table 2 showed the detection of secondary causes and coexisting diseases of hypertension, demonstrating that 1186 (39.5\%) patients had secondary causes of hypertension and coexisting diseases among 3,003 hypertensive patients. OSA was the most common, accounting for $24.7 \%$ patients (742/3003) among secondary causes and coexisting diseases, followed by PA (5.8\%), PA + OSA (4.9\%), RPD (1.8\%), and hypothyroidism (1.1\%). Endocrine hypertension was accounting for $12.1 \%$ patients (362/3003), including $10.7 \%$ of patients with PA. 281 patients with PA had bilateral excessive aldosterone production and 40 patients had unilateral excessive aldosterone production among 321 patients with PA. Less common secondary causes of hypertension were CS (4 cases, $0.10 \%$ ), PHEO (3 cases, $0.1 \%$ ), and hyperthyroidism (3 cases, $0.1 \%)$. Other secondary causes were Liddle's syndrome (1 case), aortic coarctation (1 case), and polycystic ovary syndrome (1 case), respectively.

As given in Figure 2, OSA was present in 62.6\% (742/1186) among 1186 patients of all secondary causes and coexisting diseases of hypertension and PA + OSA were present in $12.3 \%$ $(146 / 1186)$ of patients. PA was the most common endocrine cause of hypertension in our population, present in $27.1 \%$ (321/1186) of patients. RPD and RAS accounted for $6.6 \%$ in total.

As shown in Figure 3, there were overlapping conditions in secondary causes and coexisting diseases of hypertension. OSA was commonly accompanied with PA; that is, $16.4 \%$ $(146 / 888)$ of patients with OSA also had PA. In turn, $45.5 \%$ (146/321) of patients with PA were accompanied with various severity of OSA. Additionally, five patients with OSA had concomitant hypothyroidism.

Tables 3 and 4 presented the detection of top three secondary causes and coexisting diseases of hypertension in 3003 patients stratified via gender, age, and BMI. OSA was significantly higher in males than in females, and PA and anxiety were significantly higher in females than in males. OSA was the most common in each age- and BMI-stratified group, OSA and PA were significantly more prevalent in young and middle-aged subjects than in the older ones, and RPD was significantly higher in young subjects than in middleaged and older ones, whereas no significant difference was observed in anxiety among different age groups. As BMI 
TABLE 2: Detection of secondary causes and coexisting diseases in hypertensive patients.

\begin{tabular}{|c|c|c|c|}
\hline Diseases & $N$ & $\begin{array}{l}\text { Total, } \% \\
n=3987\end{array}$ & $\begin{array}{l}\text { patients with further evaluation, } \% \\
\qquad n=3003\end{array}$ \\
\hline Secondary causes and coexisting diseases & 1186 & 29.7 & 39.5 \\
\hline OSA & 742 & 18.6 & 24.7 \\
\hline $\mathrm{PA}$ & 175 & 4.4 & 5.8 \\
\hline $\mathrm{PA}+\mathrm{OSA}$ & 146 & 3.7 & 4.9 \\
\hline RPD & 54 & 1.3 & 1.8 \\
\hline Hypothyroidism & 31 & 0.8 & 1.1 \\
\hline RAS & 25 & 0.6 & 0.8 \\
\hline PHEO & 3 & 0.08 & 0.1 \\
\hline CS & 4 & 0.1 & 0.1 \\
\hline Hyperthyroidism & 3 & 0.08 & 0.1 \\
\hline Others & 3 & 0.08 & 0.1 \\
\hline
\end{tabular}

PA, primary aldosteronism; OSA, obstructive sleep apnea; RPD, renal parenchymal disease; RAS, renal artery stenosis; PHEO, pheochromocytoma; CS, Cushing's syndrome; others include one Liddle's syndrome, one aortic coarctation, and one multicystic ovary syndrome.

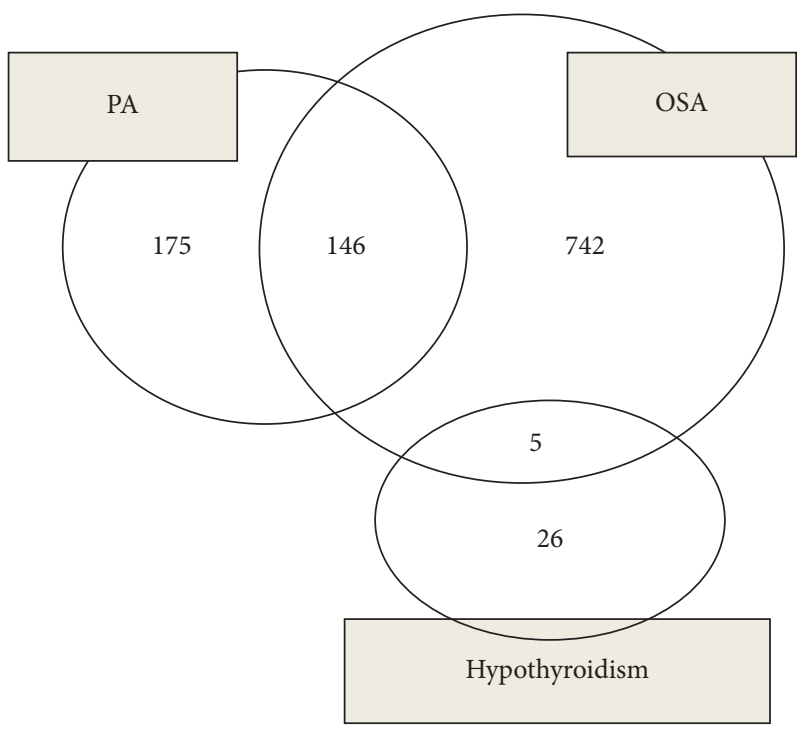

FIGURE 3: The frequency of overlapping conditions in secondary causes of hypertension. OSA, obstructive sleep apnea; RPD, renal parenchymal disease; PA, primary aldosteronism.

elevated, detection of OSA significantly increased (linear-tolinear $P<0.001$ for both). Inversely, detection of anxiety significantly decreased along with BMI increasing (linearto-linear test, $P<0.001$ ). There was significantly higher detection of PA in nonobese subjects than in obese subjects.

\section{Discussion}

The present study systematically evaluated the secondary causes and coexisting diseases of hypertension in hypertensive patients extensive in sample size using strict protocols in the specialty center of hypertension dedicated to screening, diagnosis, and treatment service of secondary causes of hypertension in Northwest of China. The data demonstrated that the detection rate of secondary causes
TABLE 3: Detection of top three secondary causes of hypertension in 3003 patients stratified via gender, age, and BMI.

\begin{tabular}{|c|c|c|c|}
\hline Group & $\begin{array}{c}\text { OSA } \\
n=742\end{array}$ & $\begin{array}{c}\mathrm{PA} \\
n=175\end{array}$ & $\begin{array}{c}\text { RPD } \\
n=54\end{array}$ \\
\hline \multicolumn{4}{|l|}{ Gender } \\
\hline Male $(n=1597)$ & $556(34.8)$ & $85(5.3)$ & $37(2.3)$ \\
\hline Female $(n=1406)$ & $186(13.2)$ & $90(6.4)$ & $17(1.2)$ \\
\hline$P$ & $<0.001$ & 0.02 & 0.02 \\
\hline \multicolumn{4}{|l|}{ Age group } \\
\hline Age $<45(n=925)$ & $279(30.2)$ & $64(6.9)$ & $39(4.2)$ \\
\hline $45 \leq$ age $<65(n=1481)$ & $399(26.9)$ & $98(6.6)$ & $10(0.7)^{\$}$ \\
\hline Age $\geq 65(n=597)$ & $64(10.7)^{* \#}$ & $13(2.2)^{* \#}$ & $5(0.8)^{*}$ \\
\hline$P$ & $<0.001$ & $<0.001$ & $<0.001$ \\
\hline \multicolumn{4}{|l|}{ Obese status } \\
\hline $\mathrm{BMI}<24(n=663)$ & $57(8.6)$ & $49(7.4)$ & $20(3.0)$ \\
\hline $24 \leq \mathrm{BMI}<28(n=1243)$ & $293(23.6)^{9}$ & $81(6.5)$ & $22(1.8)$ \\
\hline $\mathrm{BMI} \geq 28(n=1097)$ & $392(35.7)^{8 \natural}$ & $46(4.2)^{\& \natural}$ & $12(1.1)^{\&}$ \\
\hline$P$ & $<0.001$ & 0.01 & 0.01 \\
\hline \multicolumn{4}{|c|}{$\begin{array}{l}{ }^{*} P<0.01: \text { age }<45 \text { versus age } \geq 65 \text { group; }{ }^{8} P<0.01: \text { BMI }<24 \\
\text { versus BMI } \geq 28 \text { group; }{ }^{\#} P<0.01: 45 \leq \text { age }<65 \text { versus age } \geq 65 \text { group } \\
\text { घP }<0.01: 24 \leq \text { BMI }<28 \text { versus BMI } \geq 28 \text { group; }{ }^{\$} P<0.01: \text { age }<45 \\
\text { versus } 45 \leq \text { age }<65 \text { group; }{ }^{\$} P<0.01: \text { BMI }<24 \text { versus } 24 \leq \mathrm{BMI}<28 \\
\text { group; PA, primary aldosteronism; OSA, obstructive sleep apnea; RPD, renal } \\
\text { parenchymal disease. }\end{array}$} \\
\hline
\end{tabular}

and coexisting diseases of hypertension, including endocrine diseases, RPD, RAS, and OSA, was 39.5\% among 3003 hypertensive patients. OSA and PA were the most common secondary causes and coexisting diseases of hypertension among hypertensive patients. Previous studies described that prevalence of secondary causes of hypertension ranges from $4.7 \%$ to $10.5 \%[18-20]$ and that the most common secondary causes of hypertension are RPD and RAS [21]. In these previous studies, however, OSA was not included. Based on traditional secondary causes of hypertension such as endocrine hypertension, RPD, and RAS, detection of secondary hypertension was $11.1 \%$ in this current study, slightly 
TABLE 4: Detection of coexisting conditions of hypertension in 3003 patients stratified via gender, age, and BMI.

\begin{tabular}{lccc}
\hline group & $\begin{array}{c}\text { Anxiety } \\
n=140\end{array}$ & $\begin{array}{c}\text { Diabetes } \\
n=611\end{array}$ & $\begin{array}{c}\text { Obesity } \\
n=1057\end{array}$ \\
\hline Gender & & & \\
$\quad$ Male $(n=1597)$ & $35(2.2)$ & $334(20.9)$ & $626(39.2)$ \\
Female $(n=1406)$ & $105(7.5)$ & $277(19.7)$ & $431(30.7)$ \\
$P$ & $<0.001$ & 0.41 & $<0.001$ \\
Age group & & & \\
Age $<45(n=925)$ & $40(4.3)$ & $99(10.7)$ & $366(39.6)$ \\
$45 \leq$ age $<65(n=1481)$ & $67(4.5)$ & $345(23.3)^{\$}$ & $532(35.9)$ \\
Age $\geq 65(n=597)$ & $33(5.5)$ & $167(28.0)^{*}$ & $159(26.6)^{* \#}$ \\
$P$ & 0.52 & $<0.001$ & $<0.001$ \\
Obese status & & & \\
BMI $<24(n=663)$ & $57(8.6)$ & $102(15.4)$ & - \\
$24 \leq$ BMI $<28(n=1243)$ & $56(4.5)^{q}$ & $236(19.0)$ & - \\
BMI $\geq 28(n=1097)$ & $27(2.5)^{\& 4}$ & $273(24.9)^{\& 4}$ & - \\
$P$ & $<0.001$ & $<0.001$ & \\
\hline
\end{tabular}

${ }^{*} P<0.01$ : age $<45$ versus age $\geq 65$ group; ${ }^{8} P<0.01:$ BMI $<24$ versus BMI $\geq 28$ group; ${ }^{\#} P<0.01: 45 \leq$ age $<65$ versus age $\geq 65$ group; ${ }^{\natural} P<0.01: 24 \leq$ BMI $<28$ versus $\mathrm{BMI} \geq 28$ group; ${ }^{\$} P<0.01$ : age $<45$ versus $45 \leq$ age $<65$ group; ${ }^{\circ} P<0.01$ : BMI $<24$ versus $24 \leq \mathrm{BMI}<28$ group.

higher than that in previous studies (4.7-10.5\%). There exists a wide interval range in the previously reported prevalence (4.7-10.5\%) of secondary hypertension, with the possible reasons that clinical characteristics of study subjects, systemic screening, or secondary hypertension and awareness of both clinicians and patients on secondary hypertension differed greatly.

Prevalence of secondary causes of hypertension has been encountered with increasing frequency in recent years. A recent study evaluating secondary causes of true resistant hypertension in patients aged 19 to 65 years showed that OSA was present in $71.2 \%, \mathrm{PA}$ in $15.7 \%$, and RAS in $5.4 \%$ [4]. Meanwhile, detection rate of secondary causes of hypertension increased gradually, from $14.7 \%$ in 2005 to $39.3 \%$ in 2008 in our center from 1999 to 2008 [22, 23], possibly attributable to the gradual improvement in screening skills of secondary hypertension. Constituent ratio of secondary causes of hypertension has also changed. Prevalence of OSA and PA is higher in the current study than in previous data of our center, possibly indicating the underestimated prevalence of secondary causes and coexisting diseases of hypertension in the past since some patients with secondary hypertension may not have been identified successfully.

OSA is considered an important independent risk factor for cardiovascular diseases in general, especially for hypertension [24], and prominent in European and American guidelines as an identifiable and treatable cause of secondary hypertension $[6,25,26]$. Evidence is gradually accumulating that OSA is common in the condition of hypertension, ranging from 37 to $56 \%[27,28]$, and even higher among patients with resistant hypertension, reportedly between 70 and $83 \%[29,30]$. In a prospective cohort study, subjects with moderate to severe OSA (AHI $\geq 15 / \mathrm{h}$ ) showed a 3.2-fold increase in the odds of developing hypertension, compared with subjects without OSA [31]. OSA is seen in $71 \%$ of those with resistant hypertension versus $38 \%$ of those with controlled hypertension [29]. Some studies also showed that treatment of OSA with continuous positive airway pressure induces significant $\mathrm{BP}$ reduction [32,33]. Our data also shows that OSA is the most common secondary cause of hypertension in total subjects and in all age- and BMIstratified groups.

Consistent with previous studies, present study also observed that PA is diagnosed in $10.7 \%$ of hypertensive patients. Prevalence of PA was initially estimated to be 1$2 \%$, whereas it has been recently reported to be $5-16.6 \%$ in patients with hypertension $[34,35]$ and $17-23 \%$ in those with resistant hypertension [34]. Such increase in prevalence of PA might be partly due to the more frequent use of ARR as screening test, particularly in patients without hypokalemia.

A novel finding in our study is that several patients had multiple secondary causes, including 146 patients with $\mathrm{PA}+\mathrm{OSA}$ and 5 with OSA + hypothyroidism. Previous studies have shown that severity of OSA is related to the degree of aldosterone excess and that it is greater in resistant hypertension with hyperaldosteronism [36, 37]. Therefore, we consider hypertension a cardiovascular syndrome related to many systems and believe that hypertension can be caused through multiple mechanisms.

A recent systematic review and meta-analysis suggests that there is an association between anxiety and increased risk of hypertension [38]. Individuals with anxiety have a higher risk of hypertension than those without [39, 40]. Previous studies have reported that prevalence of anxiety is $9.5 \%$ in hypertensive patients [41]. BP in patients with anxiety reached target goal $(<140 / 90 \mathrm{mmHg})$ after antianxiety treatment in our study. Possible reasons for comparatively lower detection of anxiety in our study might be direct reference of mental disorders to the mental specialty clinic. Similarly, hypertensive patients with RPD are referred directly to a renal clinic, consequently, decreasing its frequency in our subjects.

In the current study, OSA and PA were observed to be the most common secondary causes of hypertension and coexisting disease in males; PA were in females. Patients with OSA were characterized by male gender, younger to middleage, and higher BMI, patients with PA were characterized by female gender, younger to middle-age, and higher BMI, and patients with anxiety were by female gender and lower BMI. Patients with RPD were seen more in males and in those with $\mathrm{BMI}<24 \mathrm{~kg} / \mathrm{m}^{2}$ in our study.

The current study, however, contains some limitations. First, specialist bias might be present since all the subjects had been referred to the hypertension specialty center. Second, this is a single center study, only showing detection of secondary causes and coexisting diseases from single hypertension center in Northwest of China. Therefore, our data may not represent the prevalence of secondary causes of hypertension in general hypertensive population. Third, the current study was not involved in a detailed investigation in all hypertensive patients. Patients with positive initial screening performed additional exams, which may have underestimated the real prevalence of several secondary 
forms of hypertension. Fourth, we have not flowed up these patients with secondary hypertension to observe the specific treatment effects such as continuous positive airway pressure and adrenalectomy, whereas the follow-up work is planned to be performed recently within the nearest future, and we might obtain further evidence on the effects of pathogenetic cause-specific treatment in this population.

In conclusion, this study shows that the detection rate of secondary causes and coexisting diseases in hypertensive patients is $39.5 \%$ in a specialty center for hypertension in Northwest China. OSA and PA were the common secondary causes of hypertension. Findings from the current study suggest an increasing frequency of secondary forms of hypertension, highlighting the burden of OSA and PA in hypertensive patients.

\section{Conflicts of Interest}

The authors declare that they have no conflicts of interest.

\section{Acknowledgments}

The authors are very grateful to all the staff of the Center of Hypertension in Xinjiang for their support with the medical examinations and demographic data collection. The study was supported by the Special Fund for Key Laboratory of Xinjiang Uygur Autonomous Region (2014KL014).

\section{References}

[1] S. Yusuf, S. Hawken, S. Ounpuu et al., "Effect of potentially modifiable risk factors associated with myocardial infarction in 52 countries (the INTERHEART study): case-control study," Lancet, vol. 364, pp. 937-952, 2004.

[2] H. Sui, W. Wang, H.-Y. Cheng, Y.-F. Cheng, L.-S. Liu, and W. Zhange, "Characterization, risk stratification and the hypertension control rate at hospital-based clinics: A survey of 25,336 hypertensives in Beijing, Shanghai and Guangzhou," Internal Medicine, vol. 52, no. 17, pp. 1863-1867, 2013.

[3] D. Li, J. Lv, F. Liu et al., "Hypertension burden and control in mainland China: Analysis of nationwide data 2003-2012," International Journal of Cardiology, vol. 184, no. 1, pp. 637-644, 2015.

[4] E. Florczak, A. Prejbisz, E. Szwench-Pietrasz et al., "Clinical characteristics of patients with resistant hypertension: the RESIST-POL study," Journal of Human Hypertension, vol. 27, no. 11, pp. 678-685, 2013.

[5] R. P. Pedrosa, L. F. Drager, C. C. Gonzaga et al., "Obstructive sleep apnea: the most common secondary cause of hypertension associated with resistant hypertension," Hypertension, vol. 58, no. 5, pp. 811-817, 2011.

[6] A. V. Chobanian, G. L. Bakris, and H. R. Black, "Seventh report of the Joint National Committee on prevention, detection, evaluation, and treatment of high blood pressure," Hypertension, vol. 42, no. 6, pp. 1206-1252, 2003.

[7] E. O’Brien, R. Asmar, L. Beilin et al., "European Society of Hypertension recommendations for conventional, ambulatory and home blood pressure measurement," Journal of Hypertension, vol. 21, no. 5, pp. 821-848, 2003.
[8] S. F. Rimoldi, U. Scherrer, and F. H. Messerli, "Secondary arterial hypertension: When, who, and how to screen?" European Heart Journal, vol. 35, no. 19, pp. 1245-1254, 2014.

[9] A. T. Hirsch, Z. J. Haskal, N. R. Hertzer et al., "ACC/AHA 2005 Practice Guidelines for the Management of Patients With Peripheral Arterial Disease (Lower Extremity, Renal, Mesenteric, and Abdominal Aortic)A Collaborative Report from the American Association for Vascular. Surgery/Society for Vascular Surgery, Society for Cardiovascular Angiography and Interventions, Society for Vascular Medicine and Biology, Society of Interventional Radiology, and the ACC/AHA Task Force on Practice Guidelines(Writing Committee to Develop Guidelines for the Management of Patients With Peripheral Arterial Disease)[J]," circulation, vol. 3, pp. 547-550, 2006.

[10] J. W. Funder, R. M. Carey, C. Fardella et al., "Case detection, diagnosis, and treatment of patients with primary aldosteronism: an endocrine society clinical practice guideline," Journal of Clinical Endocrinology and Metabolism, vol. 93, no. 9, pp. 3266-3281, 2008.

[11] N.-F. Li, H.-J. Li, D.-L. Zhang et al., "Genetic Variations in the KCNJ5 Gene in Primary Aldosteronism Patients from Xinjiang, China," PLoS ONE, vol. 8, no. 1, Article ID e54051, 2013.

[12] J. W. M. Lenders, Q.-Y. Duh, and G. Eisenhofer, "Pheochromocytoma and paraganglioma : an endocrine society clinical practice guideline," Journal of Clinical Endocrinology and Metabolism, vol. 99, no. 6, pp. 1915-1942, 2014.

[13] L. K. Nieman, B. M. Biller, and J. W. Findling, "The diagnosis of Cushing's syndrome: an Endocrine Society Clinical Practice Guideline," The Journal of Clinical Endocrinology \& Metabolism, vol. 93, no. 5, pp. 1526-1540, 2008.

[14] L. J. Epstein, D. Kristo, P. J. Strollo Jr., N. Friedman, A. Malhotra, S. P. Patil et al., "Clinical guideline for the evaluation, management and long-term care of bstructive sleep apnea in adults," Journal of Clinical Sleep Medicine, vol. 5, pp. 263-276, 2009.

[15] Clinical practice guidelines, "Management of anxiety disorders," The Canadian Journal of Psychiatry, vol. 51, p. 623, 2006.

[16] S. A. C. Simoese, E. A. Oliveira, C. R. Gomes, F. S. Lima, and J. S. S. Diniz, "Liddle's syndrome: Late diagnosis of a rare cause of arterial hypertension," Jornal de Pediatria, vol. 78, no. 3, pp. 251-254, 2002.

[17] J. Vrbikova and V. Hainer, "Obesity and polycystic ovary syndrome," Obesity Facts, vol. 2, no. 1, pp. 26-35, 2009.

[18] M. Danielson and B. Dammström, "The Prevalence of Secondary and Curable Hypertension," Acta Medica Scandinavica, vol. 209, no. 1-6, pp. 451-455, 1981.

[19] G. H. Anderson, N. Blakeman, and D. H. P. Streeten, “The effect of age on prevalence of secondary forms of hypertension in 4429 consecutively referred patients," Journal of Hypertension, vol. 12, no. 5, pp. 609-615, 1994.

[20] M. Omura, J. Saito, K. Yamaguchi, Y. Kakuta, and T. Nishikawa, "Prospective study on the prevalence of secondary hypertension among hypertensive patients visiting a general outpatient clinic in Japan," Hypertension Research, vol. 27, no. 3, pp. 193-202, 2004.

[21] D. A. Calhoun, D. Jones, S. Textor, D. C. Goff, T. P. Murphy, R. D. Toto et al., "American Heart Association Professional Education Committee. Resistant hypertension: diagnosis, evaluation, and treatment: ascientific statement from the American Heart Association Professional Education Committee of the Council for High Blood Pressure Research," Hypertension, vol. 51, no. 6, pp. 1403-1419, 2008. 
[22] N. F. Li, L. Lin, L. Wang, X. L. Wang, F. Y. Zu, D. L. Zhang et al., "Etiology analysis for hospitalized hypertensive patients: 10 years report from the department of hypertension (1999 2008)," Zhonghua Xin Xue Guan Bing Za Zhi, vol. 38, pp. 939942, 2010.

[23] N.-F. Li, L. Wang, K.-M. Zhou et al., "Analysis of etiology of the patients with hypertension from the People's Hospital of Xinjiang Uygur Autonomous Region," Zhonghua xin xue guan bing za zhi [Chinese journal of cardiovascular diseases], vol. 35, no. 9, pp. 865-868, 2007.

[24] C. A. A. Chahal and V. K. Somers, "Secondary hypertension: Obstructive sleep apnea," Journal of the American Society of Hypertension, vol. 9, no. 3, pp. 244-247, 2015.

[25] G. Parati, C. Lombardi, J. Hedner et al., "Position paper on the management of patients with obstructive sleep apnea and hypertension: Joint recommendations by the European Society of Hypertension, by the European Respiratory Society and by the members of European COST (COoperation in Scientific and Technological research) ACTION B26 on Obstructive Sleep Apnea," Journal of Hypertension, vol. 30, no. 4, pp. 633-646, 2012.

[26] L. Grote, J. Hedner, and J. H. Peter, "Sleep-related breathing disorder is an independent risk factor for uncontrolled hypertension," Journal of Hypertension, vol. 18, no. 6, pp. 679-685, 2000.

[27] C. Sjöström, E. Lindberg, A. Elmasry, A. Hägg, K. Svärdsudd, and C. Janson, "Prevalence of sleep apnoea and snoring in hypertensive men: A population based study," Thorax, vol. 57, no. 7, pp. 602-607, 2002.

[28] L. F. Drager, P. R. Genta, R. P. Pedrosa, F. B. Nerbass, C. C. Gonzaga, E. M. Krieger et al., "Characteristics and Predictors of Obstructive Sleep Apnea in Patients With Systemic Hypertension," American Journal of Cardiology, vol. 105, no. 8, pp. 11351139, 2010.

[29] S. C. Gonçalves, D. Martinez, M. Gus et al., "Obstructive sleep apnea and resistant hypertension: A case-control study," Chest, vol. 132, no. 6, pp. 1858-1862, 2007.

[30] A. G. Logan, S. M. Perlikowski, A. Mente et al., "High prevalence of unrecognized sleep apnoea in drug-resistant hypertension," Journal of Hypertension, vol. 19, no. 12, pp. 2271-2277, 2001.

[31] P. E. Peppard, T. Young, M. Palta, and J. Skatrud, "Prospective study of the association between sleep-disordered breathing and hypertension," The New England Journal of Medicine, vol. 342, no. 19, pp. 1378-1384, 2000.

[32] F. Barbé, J. Durán-Cantolla, M. Sánchez-de-la-Torre et al., "Effect of continuous positive airway pressure on the incidence of hypertension and cardiovascular events in nonsleepy patients with obstructive sleep apnea: a randomized controlled trial," Journal of the American Medical Association, vol. 307, no. 20, pp. 2161-2168, 2012.

[33] J. M. Marin, A. Agusti, I. Villar et al., "Association between treated and untreated obstructive sleep apnea and risk of hypertension," The Journal of the American Medical Association, vol. 307, no. 20, pp. 2169-2176, 2012.

[34] G. Piaditis, A. Markou, L. Papanastasiou, I. I. Androulakis, and G. Kaltsas, "Progress in aldosteronism: A review of the prevalence of primary aldosteronism in pre-hypertension and hypertension," European Journal of Endocrinology, vol. 172, no. 5, pp. R191-R203, 2015.

[35] D. A. Calhoun, D. Jones, S. Textor et al., "Resistant hypertension: diagnosis, evaluation, and treatment. A scientific statement from the American Heart Association Professional
Education Committee of the Council for High Blood Pressure Research," Hypertension, vol. 51, no. 6, pp. 1403-1419, 2008.

[36] M. N. Pratt-Ubunama, M. K. Nishizaka, R. L. Boedefeld, S. S. Cofield, S. M. Harding, and D. A. Calhoun, "Plasma aldosterone is related to severity of obstructive sleep apnea in subjects with resistant hypertension," Chest, vol. 131, no. 2, pp. 453-459, 2007.

[37] C. C. Gonzaga, K. K. Gaddam, M. I. Ahmed, E. Pimenta, S. J. Thomas, S. M. Harding et al., "Severity of obstructive sleep apnea is related to aldosterone status in subjects with resistant hypertension," Journal of Clinical Sleep Medicine, vol. 6, pp. 363368, 2010.

[38] Y. Pan, W. Cai, Q. Cheng, W. Dong, T. An, and J. Yan, "Association between anxiety and hypertension: A systematic review and meta-analysis of epidemiological studies," Neuropsychiatric Disease and Treatment, vol. 11, pp. 1121-1130, 2015.

[39] D. J. Stein, S. Aguilar-Gaxiola, J. Alonso et al., "Associations between mental disorders and subsequent onset of hypertension," Journal of Psychiatric Research, vol. 36, pp. 142-149, 2014.

[40] S. L. Bacon, T. S. Campbell, A. Arsenault, and K. L. Lavoie, "The impact of mood and anxiety disorders on incident hypertension at one year," International Journal of Hypertension, vol. 2014, Article ID 953094, 2014.

[41] J. Han, X. M. Yin, F. Xu, X. Hong, Y. Q. Liang, and Z. Y. Wang, "A case-control study on depression and anxiety in hypertensive patients," Zhonghua Liu Xing Bing Xue Za Zhi, vol. 29, pp. 125127, 2008. 


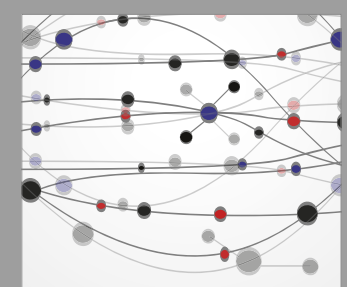

The Scientific World Journal
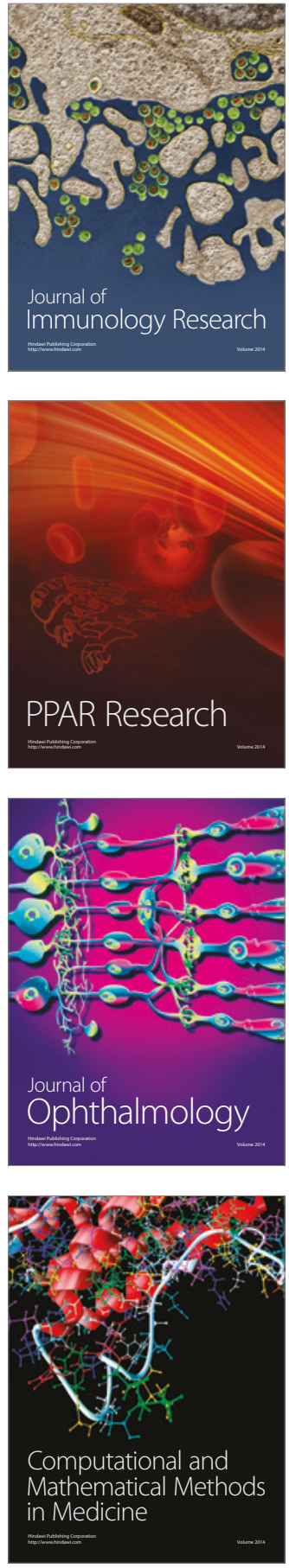

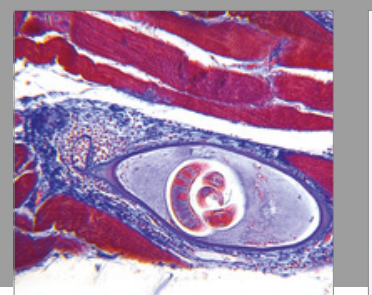

Gastroenterology Research and Practice
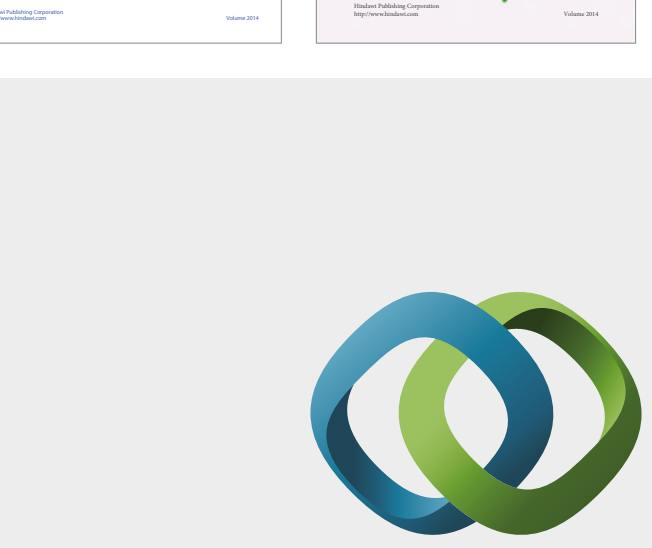

\section{Hindawi}

Submit your manuscripts at

https://www.hindawi.com
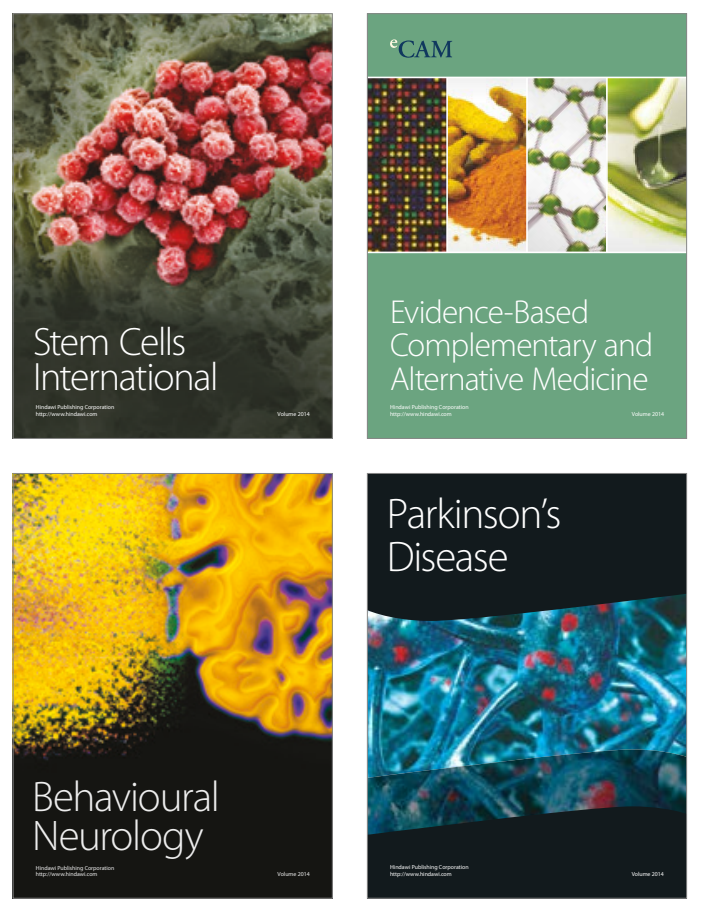
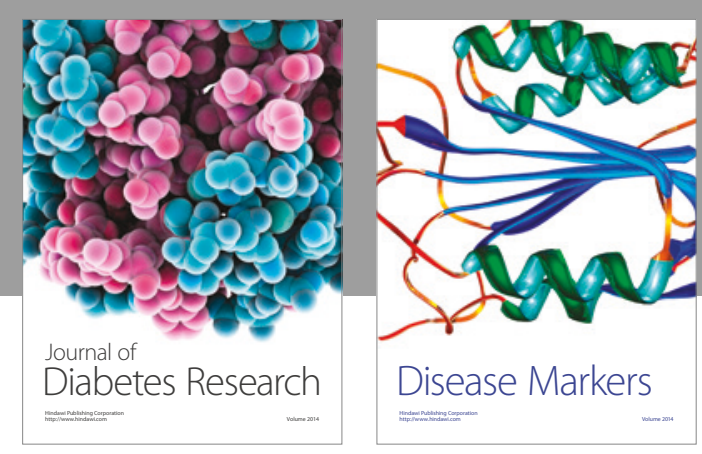

Disease Markers
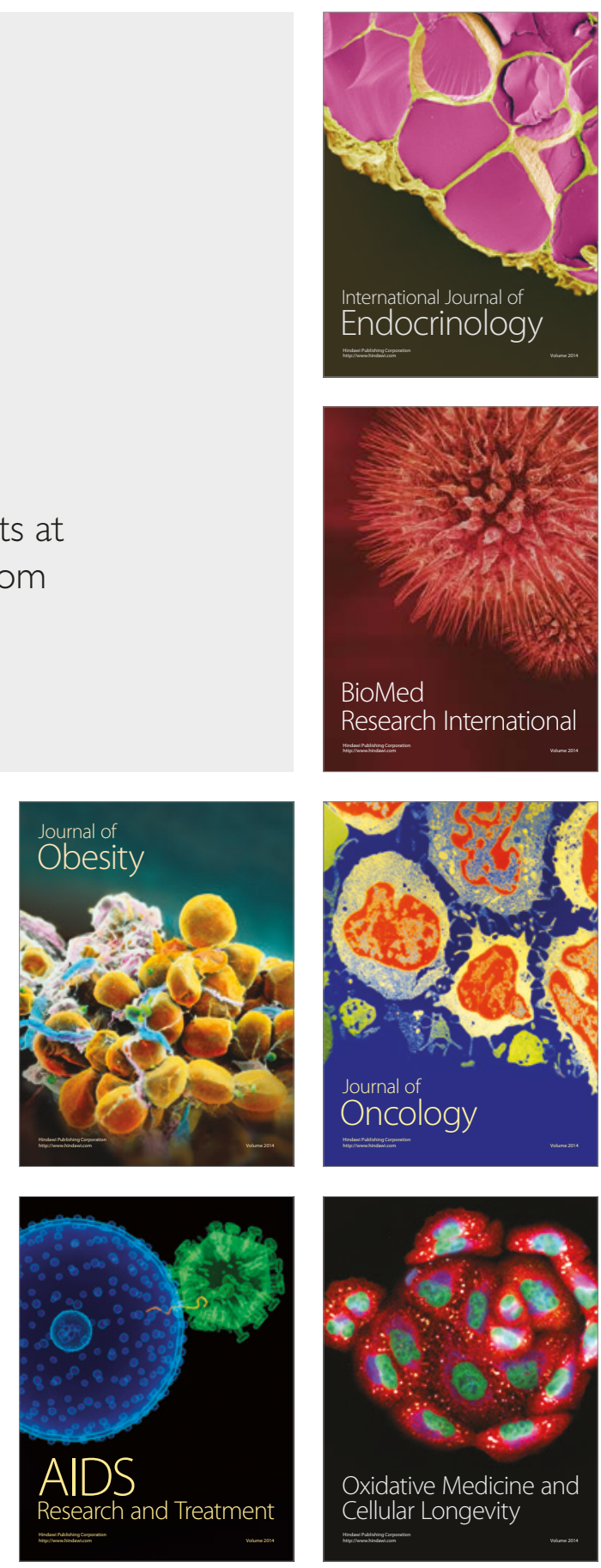